\title{
A modified collaborative model to improve surgical flow health care processes in Veterans Affairs Medical Centers
}

\author{
Balmatee Bidassie*1, William Gunnar ${ }^{2}$, Leigh Starr ${ }^{3}$, George Van Buskirk ${ }^{3}$, Lisa J Warner ${ }^{4}$, Clifford Anckaitis ${ }^{3}$ \\ ${ }^{1}$ Clinical Partnerships in Healthcare Transformation (CPHT), VA Center for Applied Systems Engineering (VA-CASE), Veterans \\ Engineering Resource Center (VERC), Indianapolis IN, United States \\ ${ }^{2}$ VHA National Surgery Office and The George Washington University, Washington DC, United States \\ ${ }^{3}$ VHA Office of Systems Redesign and Improvement, Washington DC, United States \\ ${ }^{4}$ VHA Office of Nursing Services, Washington DC, United States
}

Received: February 7, 2017

DOI: $10.5430 /$ ijh.v3n2p47
Accepted: May 24, 2017

Online Published: July 27, 2017

\begin{abstract}
The Veterans Health Administration (VHA) Office of Systems Redesign and Improvement, in collaboration with the VHA National Surgery Office and Veterans Affairs Center for Applied Systems Engineering (VA-CASE) - Veterans Engineering Resource Center (VERC), conducted a national process improvement initiative in Fiscal Year 2012 to promote more effective and efficient use of surgical unit resources. This improvement effort adopted a modified collaborative model with the incorporation of symposia and Rapid Process Improvement Workshops (RPIWs) to address concerns from collaborative teams for a more efficient surgical flow. Throughout the seven-month duration of the initiative, 20 teams participated and completed a total of 468 Plan-Do-Study-Act (PDSA) cycles to implement changes and improve performance levels in defined measures. At the conclusion, on average, teams were able to improve performance on the first case on-time start rate by $24 \%$, mean turnover time by $14 \%$, cancellation rate by $5 \%$, and Operating Room (OR) utilization by $8 \%$. The projected annual Cost Savings was estimated to be nearly $\$ 25$ million. This modified improvement model overcame some of the challenges experienced in a traditional improvement collaborative model such as lack of clarity of clear roles and responsibilities of team members and clear and consistent aims. The operations in surgical flow were improved in multiple ways to achieve overall better performance. Future improvement initiatives have the potential to further enhance performance outcomes by focusing even more efforts on the preparation phase, increasing team participation and leadership buy-in, utilizing on-going reports that track team progress and focusing on sustain and spread.
\end{abstract}

Key Words: Collaborative, Surgical flow, Health care process improvement, Veterans

\section{INTRODUCTION}

Surgical flow has been identified as a critical area that highly impacts every work flow in a hospital. The operating room $(\mathrm{OR})$ is one of the most critical facility resources and one of the most expensive ${ }^{[1]}$ and as a result consumes a large portion of a hospital's funds. ${ }^{[2]}$ In Fiscal Year 2012, the Veterans Health Administration (VHA) completed over 395,000 surgical cases and spent more than 6 million hours conduct-

\footnotetext{
*Correspondence: Balmatee Bidassie; Email: Balmatee.bidassie@ va.gov; Address: Clinical Partnerships in Healthcare Transformation (CPHT), VA Center for Applied Systems Engineering (VA-CASE), Veterans Engineering Resource Center (VERC), Indianapolis IN, United States.
} 
ing surgeries with over 3 million intra-operative Work Resource Value Units (wRVUs) expended. Given the significant workload generated by VHA surgical units, VHA National Surgery Office (NSO) collaborated with the VHA Office of Systems Redesign and Improvement (SR) to execute an improvement initiative with the objective of improving OR flow, efficiency, and operations using core process improvement (PI) methods. To achieve this goal, NSO and SR partnered with the Veterans Affairs-Center for Applied Systems Engineering (VA-CASE), for their PI and engineering resource expertise, to conduct a process improvement initiative in Fiscal Year 2012.

VA-CASE is an interdisciplinary Veterans Engineering Resource Center (VERC) located in the Midwest USA. This center is built on a philosophy of "paired leadership" of operational systems engineering faculty with VHA administrative and clinical management and staff. The focus of this center is to employ strategies to accelerate integration of operational systems engineering within VA healthcare delivery systems in order to promote systems improvement. VA-CASE leverages the significant operational systems engineering, informatics and implementation science expertise present within Veterans Affairs Medical Centers (VAMCs) and affiliated academic partners to transform VHA healthcare delivery systems.

The VHA Office of SR focuses on and deploys numerous PI initiatives across VHA to improve patient flow and enhance system effectiveness within the VA healthcare system. Some of these PI initiatives are conducted utilizing a collaborative improvement method modelled after the Institute for Healthcare Improvement (IHI) breakthrough series. ${ }^{[3]}$ The IHI Collaborative model is a flexible approach that enables participating teams to contribute different perspectives to the improvement process. The VHA Office of SR has applied the IHI Collaborative model to optimize care quality and efficiency in numerous hospital settings and related to varying processes with encouraging results observed ${ }^{[4-8]}$ and continuing to be demonstrated.

The conceptual framework of the collaborative proposed by VA-CASE was based on a "modification" of the IHI Collaborative model using a pilot study consisting of 20 teams. Each team represented one VAMC from each of 20 participating Veterans Integrated Service Networks (VISNs) to address areas for improvement in ORs. The goal of the initiative was to successfully enable multiple VISNs/VAMCs to collaborate to improve processes, share strategies and lessons learned, and focus on sustaining achievements and spreading strong practices to other VAMCs within their respective VISNs.

In this paper, we present an overview of the traditional IHI
Collaborative model and the challenges raised by this model, as well as introduce the modified Collaborative model proposed by the VERC and piloted in Fiscal Year 2012. Additionally, we will review the improvements achieved in surgical flow using this modified model, the impact on participating teams and lessons learned.

\section{METHODS}

\subsection{Overview of IHI Collaborative model}

The IHI developed the Breakthrough Series, a model for health care facilities to achieve process and quality improvement. ${ }^{[3]}$ The series was designed to be conducted via collaborative learning and has contributed significant success to participating teams.

Before the first Learning Session, a topic for the series is selected and then subject matter experts in the relevant disciplines are recruited to assist in creating the Collaborative framework and contents. After the Collaborative planning is complete, IHI starts the acceptance of applications and conducts pre-work conference calls with teams to help familiarize them with Collaborative processes.

During the first Learning Session, the faculty presents the ideal state of care in the selected topic, and the teams are taught the Model for Improvement, or Plan-Do-Study-Act (PDSA) cycles, to facilitate implementation of change ideals. ${ }^{[9,10]}$ The PDSAs enable multidisciplinary teams to investigate quality problems, develop and implement small scale changes, measure the effects, and make various changes that improve a specific process. ${ }^{[11]}$ There are two additional learning sessions that succeed the first, which allow teams to share success stories, exchange ideas, and discuss barriers. Between each Learning Session, there is an Action Period during which teams test and implement change ideas locally. The achievements are measured and documented at the conclusion of the Collaborative for the expansion of knowledge to other health care systems.

Although the IHI Collaborative model expresses achievement in various objectives, there are several challenges identified by the Collaborative teams. ${ }^{[12]}$ Teams come to the first Learning Session without full preparation, clarification of roles and responsibilities, agreed upon aims, and/or an understanding of the improvement methods. Additionally, teams seek management involvement/support from senior management, however it is not always guaranteed. Senior management involvement/support has been identified as one of the key elements to the success of teams ${ }^{[13-15]}$ and is significantly associated with the degree of quality improvement implementation. ${ }^{[16]}$ 


\subsection{Modified Collaborative model}

In an attempt to address the challenges in the literature of implementing an IHI Collaborative model, the Modified Collaborative (see Figure 1) placed great emphasis on 1) clearly defining objectives and allocating organization resources; 2) defining roles of team members and expectations for Col- laborative participation; 3) team building and preparation for the Collaborative, including senior leadership involvement; 4) mutual learning versus teaching; 5) measurable and achievable targets; 6) the ability to address data and change challenges; and 7) sustainability.

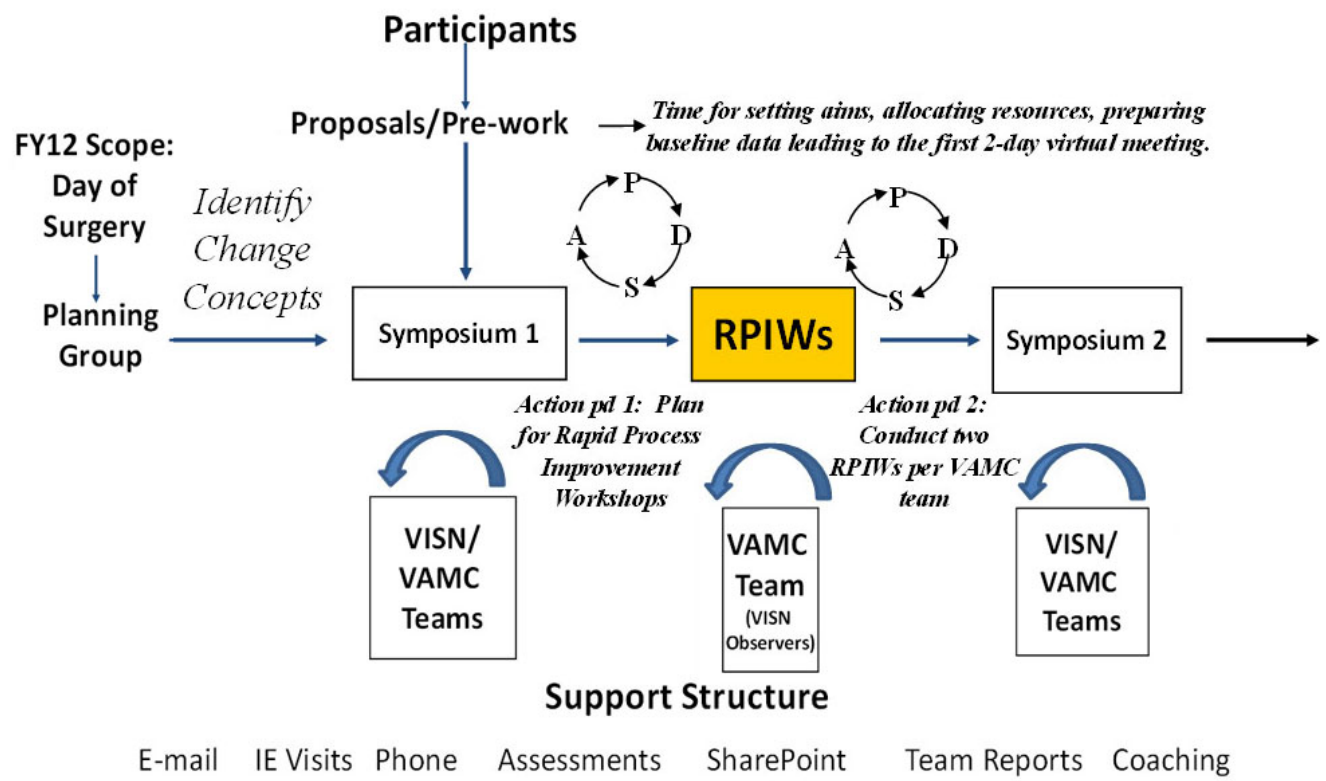

Figure 1. Modified Collaborative model

The following are key components of the Modified Collaborative model:

(1) Pre-work: Activities encouraged teams to collect as much information about their current processes as possible and identify improvement opportunities before Symposium 1 (Learning Session 1). This better prepared them for PI activities and addressed challenges of team formation, resource allocation, and ambiguous aims. Therefore, time was more efficiently spent on the PDSA cycles during site visits which followed.

(2) Symposia: Conducted virtually which reduced the need for travel. Hence, more people were able to participate in the Learning Sessions and support the spread of PI ideas which enhanced the buy-in of all members to resolve issues related to disagreements on aims, for example. This also eliminated miscommunication concerns that occurred when travelers transferred contents of the Learning Sessions to their "home team" colleagues.

(3) Rapid Process Improvement Workshops (RPIWs): The local RPIWs established teams' understanding of the PI methods by testing change ideas. Rather than just learning the concepts, this understanding of the appli- cation of methods and interpretation of change concepts enables teams to expand the achievements in the future. ${ }^{[12]}$ Additionally, the on-site support of coaches and improvement experts (i.e., systems redesign advisor and data analyst) helped break down barriers and address problems encountered during pilot tests.

(4) Duration of Action Period: In the Modified Collaborative model, each Action Period lasted for two months. The quick cycle time motivated and placed pressure on teams to achieve their aims. The quick cycle time also reduced the chances of team changeover and prevented a loss of focus resulting from long improvement cycles. In addition, the two Action Periods were intended to tackle separate problems rather than the same set of aims as in the IHI Collaborative model.

(5) Leadership Involvement: VISN and facility leadership was essential to the success and sustainability of the Surgical Flow Improvement Initiative (SFII). As a method to secure critical support from leadership, before the start of the SFII, the Executive Leadership Teams at the Medical Center level and VISN Surgical Workgroups were asked for their commitment and support of the project through a formal endorsement process. 
During the Pre-work phase, core teams were formed and required to set aim statements, allocate resources, collect baseline data, and identify major issues, barriers, and PI opportunities. Each team was composed of front-line staff (i.e., surgeon representative, OR scheduler, OR nurse manager, and anesthesia lead) and improvement experts (i.e., systems redesign/improvement advisor and data analyst) to ensure that both clinical expertise and process improvement knowledge were present for valid and effective implementation of changes. A variety of tools were provided to assist teams, and to teach PI basics, including process mapping and lean concepts. Data collection routines were implemented to extract required data. Outcomes from the pre-work phase included the creation of a surgical flow value stream map, establishment of baseline data, identification and prioritization of problems in current surgical flow, and a project charter.

The primary components of the PI initiative lasted approximately seven months and consisted of two virtually conducted Symposia (similar to the Collaborative Learning Sessions). Between the Symposia, each team conducted two RPIWs, each lasting one week. The RPIW's are in-depth applications of Lean tools to assess the current state of a process and redesign current processes to meet specific improvement objectives. ${ }^{[17]}$ Action Periods were conducted after each RPIW. During the Action Periods, teams implemented changes and collected data during the two RPIWs supported by VERC industrial engineer (IE) coaches and facilitators who traveled to the local sites to support the teams. External facilitation and involvement of VERC IEs to serve in coaching roles when they were assigned to facilitate the local RPIWs through face-to-face meetings and to engage with the sites during the weekly calls and virtual Symposia throughout the course of the initiative ${ }^{[18]}$ were key features in the modified Collaborative.

During the one-week on-site RPIW event, coaches and IEs provided on-site support customized to the organization of the environment to help the teams identify the most effective PDSA cycles and prioritize the implementation plans to achieve the maximum amount of improvement. The change ideas were tested on a small scale for teams to practice the application of tools and gather an understanding of the impact of the changes for future planning. Multiple PDSA cycles were initiated to cover as many opportunities as possible. PDSA cycles not completed during the RPIW week were completed during the implementation phase that followed. Other key activities that occurred included weekly/biweekly calls of the core team, development and implementation of action plans, data collection and analysis, and preparation of routine progress reports summarizing the results of the implementation of changes.

\subsection{Data collection}

In order to evaluate PI initiatives and enable data-driven decision making, ${ }^{[19]}$ carefully planned data collection and analysis were essential. Based on the guidelines from the VHA Surgical Flow Improvement Initiative Handbook, ${ }^{[20]}$ the planning group identified four national measures to track teams' performance over the period of implementation: 1) percentage of OR first case on-time starts, 2) mean turnover times (also referred to as "lag time between cases" and measured as "wheels out" to "wheels in"), 3) OR utilization and 4) case cancellation rate. Other supporting measures include "wheels in" to incision, staff overtime, and delay in post-anesthesia care unit (PACU). To accommodate differences among facilities, the modified collaborative also encouraged teams to identify their own measures to address specific problems. In order to facilitate data collection and analysis, teams used two standardized data collection systems, both designed using Microsoft Excel, to measure performance and evaluate the success of SFII: 1) OR performance measurement tool and 2) Cost Savings Tool.

\subsubsection{OR performance measurement tool}

The OR performance measurement tool provided the teams with a mechanism to measure and track changes. Teams extracted data through standardized data collection routines at the end of each month. IEs generated performance reports and discussed the team's progress towards their set aims during their weekly call. The main components of the measurement tool included raw data sets (i.e., case information and staffing data), site information (i.e., OR settings), and trend reports (see Figure 2).

The reports consisted of tables and run/bar charts that monitored the baseline, the impacts of PDSA cycles, and the current state. Based on the information from the reports, the teams and IEs identified the problems with current processes and defined improvement opportunities.

\subsubsection{Cost savings tool}

A Cost Savings tool was designed to provide a simplified means for generating an estimate of the potential financial impact from improvements made during SFII Fiscal Year 2012. Figure 3 outlines the data collection process, the Cost Savings summary tool and the assumptions applied as IEs worked with each team to generate reports based on financial data. This includes data provided by the VAMC OR settings, baseline performance and targets, costs of RPIWs (e.g., pilot implementation costs, labor costs, and training costs, etc.), implementation costs (e.g., additional staffing and costs of each PDSA cycle), and costs of regular OR operations to calculate the Cost of Poor Quality (COPQ), as well as costs and financial benefits of making changes. The COPQ includes 
costs from under-utilized OR time, delay of first cases, productivity loss from turnover, and staff overtime. Based on the aims of teams, potential cost savings were calculated as the reduction in COPQ through meeting targets. Some assumptions were made for the Cost Savings analysis: 1) average hourly OR labor cost was $\$ 45$; 2) 1 minute OR overhead cost was $\$ 30 ; 3$ ) RPIW impact on OR utilization, if not provided by each site, assumed to be $1 \%-2 \%$ increase; and 4) during the implementation period, teams spent 2-3 hours per week for 8 weeks on PDSA cycles. These assumptions were calculated from conservative averages of actual numbers reported by the individual facilities.

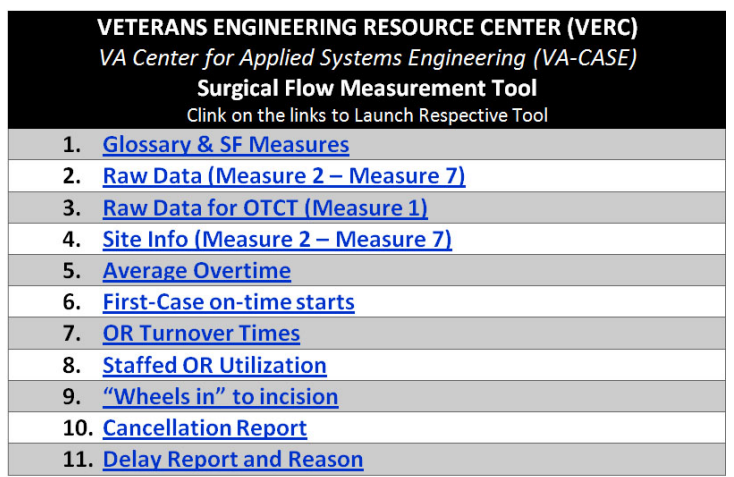

Figure 2. The navigation tab of OR performance measurement tool

\begin{tabular}{|c|c|c|c|c|c|c|c|c|}
\hline & \multicolumn{3}{|c|}{ Costs/Expenses } & \multicolumn{3}{|c|}{ COPQ } & \multirow[b]{2}{*}{ Totals } \\
\hline & & $\begin{array}{l}\text { Project } \\
\text { Costs }\end{array}$ & \multicolumn{2}{|c|}{$\begin{array}{c}\text { Implementation } \\
\text { Costs }\end{array}$} & Productivity & $\begin{array}{l}\text { Materials, } \\
\text { Equipment }\end{array}$ & $\begin{array}{c}\text { Cost/ } \\
\text { Revenue }\end{array}$ & \\
\hline $\begin{array}{l}\text { Costs/Exf } \\
\text { Year } 1\end{array}$ & & $\$ 24,583$ & $\$ 76$ & 5,680 & & & & $\$ 101,263$ \\
\hline $\begin{array}{l}\text { Potential } \\
\text { Savings } f \prime\end{array}$ & $\begin{array}{l}\text { ft } \\
n C O P Q\end{array}$ & & & & $\$ 1,560$ & & $\$ 501,228$ & $\$ 502,788$ \\
\hline $\begin{array}{l}\text { Potential } \\
\text { Savings fi }\end{array}$ & $\begin{array}{l}\text { ard } \\
\text { n COPQ }\end{array}$ & & & & & $\$$ & $\$ 165,600$ & $\$ 165,600$ \\
\hline $\begin{array}{l}\text { Potential } \\
\text { Savings } F\end{array}$ & $\begin{array}{l}\text { et Cost } \\
t \text { Year }\end{array}$ & & & & & & & $\$ 567,125$ \\
\hline \multicolumn{9}{|c|}{ Data collection Process: } \\
\hline $\begin{array}{l}\text { Identificed most } \\
\text { important data } \\
\text { elements }\end{array}$ & $\begin{array}{c}\text { Identified core } \\
\text { requirements for } \\
\text { soft and hard } \\
\text { savings }\end{array}$ & $\rightarrow \begin{array}{c}\text { Develo } \\
\text { assumptions } \\
\text { and hard s. }\end{array}$ & & $\rightarrow \begin{array}{c}\text { DSS (Finance } \\
\text { auditing dept) } \\
\text { provided validation } \\
\text { of the average cost } \\
\text { for the data points) }\end{array}$ & $\rightarrow$\begin{tabular}{c|} 
Informed team at \\
site what data was \\
needed fort total \\
Cost Savings \\
calculation
\end{tabular}$\rightarrow$ & \begin{tabular}{|c|} 
Site collected data \\
and worked with \\
Industrial Engineer \\
to input into the \\
tool
\end{tabular} & $\begin{array}{l}\text { Consolidated } \\
\text { quarterly data }\end{array}$ & $\begin{array}{l}\text { Provided final Cost } \\
\text { Savings reports }\end{array}$ \\
\hline \multicolumn{9}{|c|}{$\begin{array}{l}\text { Definitions validated by Decision Support Service (DSS) Fiscal Services } \\
\text { - Soft Savings - Savings from indirect costs and/or opportunity costs in four areas; OR Utilization, First Time Starts, OR } \\
\text { Turnover times, and cancelling surgeries. } \\
\text { Hard Savings - Savings from either spending less money on Overtime or on supplies and equipment that could show a } \\
\text { savings in the budget } \\
\text { Calculation Assumptions (validated by each VAMC site): } \\
\text { - Average hourly labor cost (if not provided by DSS) - } \$ 45 \\
\text { - Cost of } 1 \text { OR minute (overhead cost) - } \$ 30 \\
\text { Cost of Cancelling surgery - } \$ 3,000 \text { (assumes case was not back filled) } \\
\text { Additional Assumptions } \\
\text { - All improvements/savings are not all directly/solely a result of SFII } \\
\quad \text { To prevent double counting in soft savings from the four metrics (Utilization or First Case Starts, Lag Time and } \\
\text { Cancellations) the following rules were used: } \\
\text { - Using Utilization as the default as long as it is positive increase } \\
\text { - If Utilization has decreased, used First Case Starts, Lag Time and Cancellations } \\
\text { Negative cost saving: were counted as zero assuming improvement efforts did not cause a negative performance } \\
\text { - SFII improvement efforts did not cause any negative impact on performance } \\
\text { - Verified with the sites with negative trends in performance that the negative trends were not caused by SFII improvements } \\
\text { Still counted cost of facilitation of events and cost of implementing improvements }\end{array}$} \\
\hline
\end{tabular}

Figure 3. Cost Savings tool summary page, data collection process and assumptions

Using the information discussed above, the Cost Savings was calculated by combining two approaches, calculating the hard and soft saving and then subtracting the actual costs from the total savings. The hard saving were calculated by totaling the decrease in supplies, equipment and emergency shipping costs plus the savings from a decrease in overtime while the soft saving or Costs of Poor Quality were calculated by using the unit saving for each of the OR Efficiency measures times the net change for each measures. For example, the savings for the OR Efficiency Index measure called 
Staffed OR utilization was calculated by multiplying the net additional minutes utilized times the OR overhead costs per minute times the number of ORs per facility. Totaling the Staffed OR utilization savings for all of the participating facilities resulted in the largest category of savings, $\$ 17,432,000$ found in Table 1 . The costs were calculated by adding the labor costs for the hours that each team dedicated to this effort plus training, supplies and other direct expenses.

Table 1. Projected cost savings summary

\begin{tabular}{lr}
\hline National Metrics/Other Improvements & Cost Savings Estimate \\
\hline Staffed OR utilization & $\$ 17,432,000$ \\
Operating room first case on-time starts & $\$ 2,029,173$ \\
OR Turnover times & $\$ 3,032,467$ \\
Cancellation rates & $\$ 995,000$ \\
Delay report & $\$ 710,000$ \\
“Wheels in” to incision & $\$ 391,000$ \\
VISN 21: Patient wait time for first case & $\$ 174,000$ \\
VISN 18: Timely discharge from PACU & $\$ 157,000$ \\
VISN 4: Patient Transportation & $\$ 38,000$ \\
TOTAL & $\$ 24,958,640$ \\
\hline
\end{tabular}

\section{RESUltS}

In total, 20 teams joined SFII and 40 RPIWs were completed. There was a total of 468 PDSA cycles, and the breakdown of PDSA by each measure can be seen in Figure 4.

Each facility implemented between three and 37 PDSA cycles. As expected, as teams became more comfortable with PI tools, more PDSAs were conducted in RPIW $2(n=273)$ vs. RPIW $1(n=195)$. The majority of the teams worked on PDSAs aligned with the national measures; however, some teams also focused on other PDSAs (see Figure 5).

Nine teams worked on OR first case on-time starts (see Figure $6)$ and $67 \%(n=6)$ of teams showed significant improvement. Overall, there was an average relative improvement of $24 \%$. While the most successful facility had relative improvement, there were some teams that either retained the same performance level or performed lower than their baseline.

Sixteen teams aimed to reduce the mean turnover times (see Figure 6$)$ and $63 \%(n=10)$ of the teams showed decrease in their mean turnover time. While a few teams did not realize improvements, overall the average relative improvement was a $14 \%$ reduction in turnover time.

Eight teams focused on improving OR utilization (see Figure $6)$, with $75 \%(n=6)$ of the teams realizing an improvement in utilization, with the average relative improvement of all teams being $8 \%$.

Six facilities attempted to reduce case cancellation rates (see Figure 6$)$, with $50 \%(n=3)$ of the teams successfully reducing case cancellation rates, and the average relative reduction of all teams at $5 \%$.

The projected annual estimated Cost Savings was nearly $\$ 25$ million (see Table 1). As a majority of teams worked on the core national measures, they also generated additional, qualitative benefits. Most of the financial savings was derived from the improvement in OR utilization $(\$ 17,432,000)$. Although the potential savings from PI varied from "aim" to "aim" statements, the overall savings were greater than the costs of making changes, generating a positive overall Cost Savings.

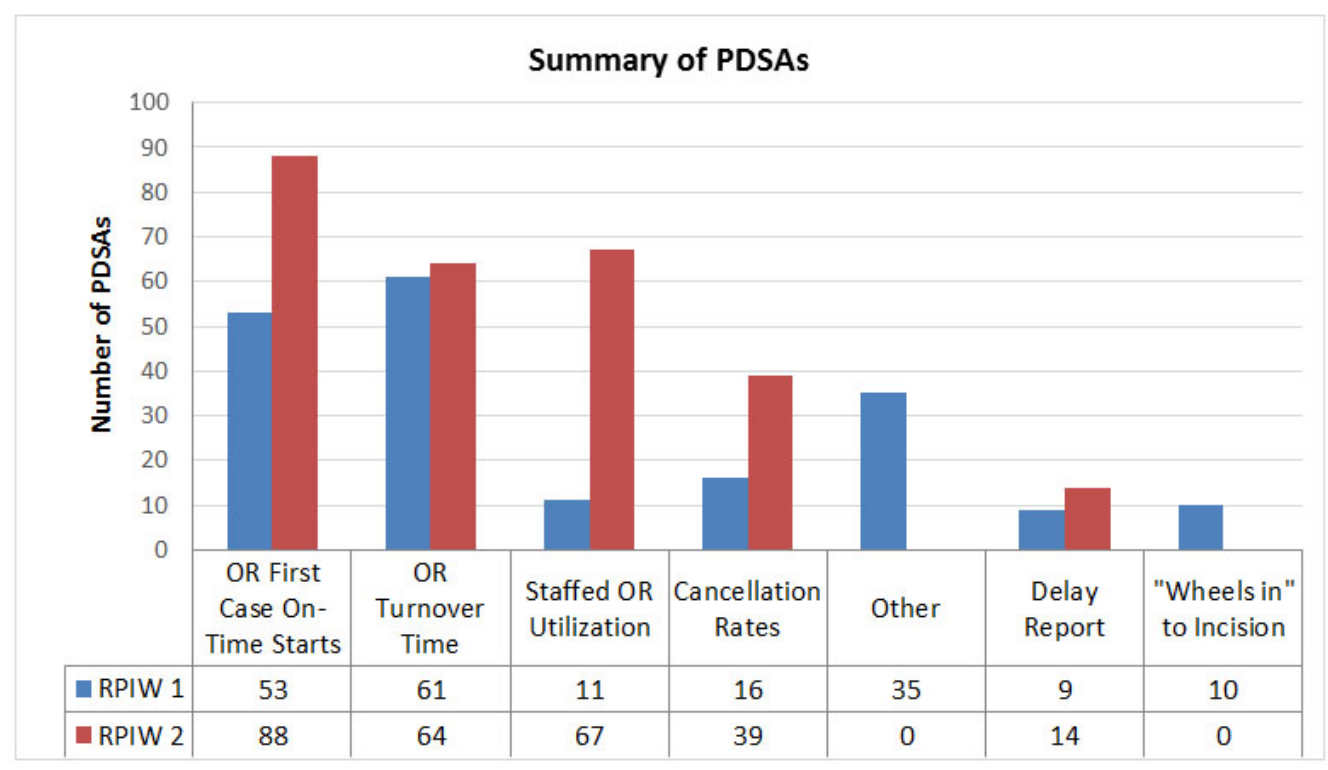

Figure 4. Summary of PDSA by National Measures 


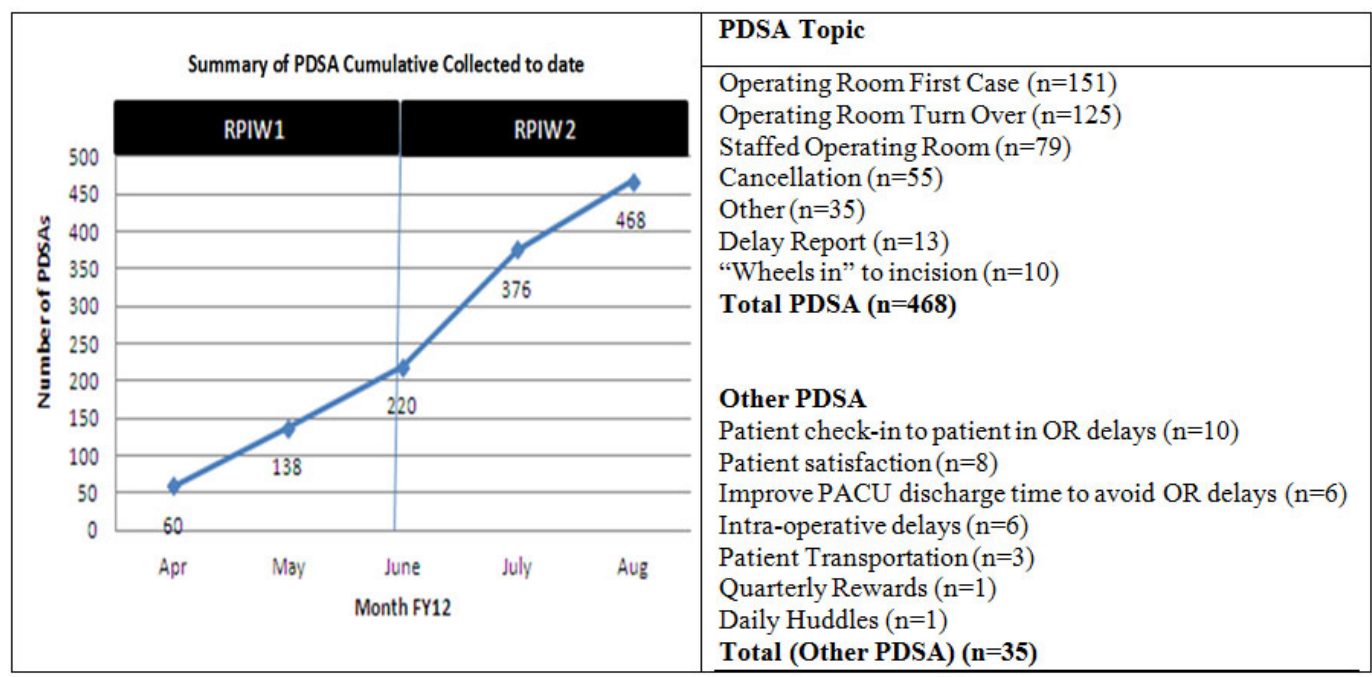

Figure 5. Trend of PDSA across RPIW 1 and RPIW 2
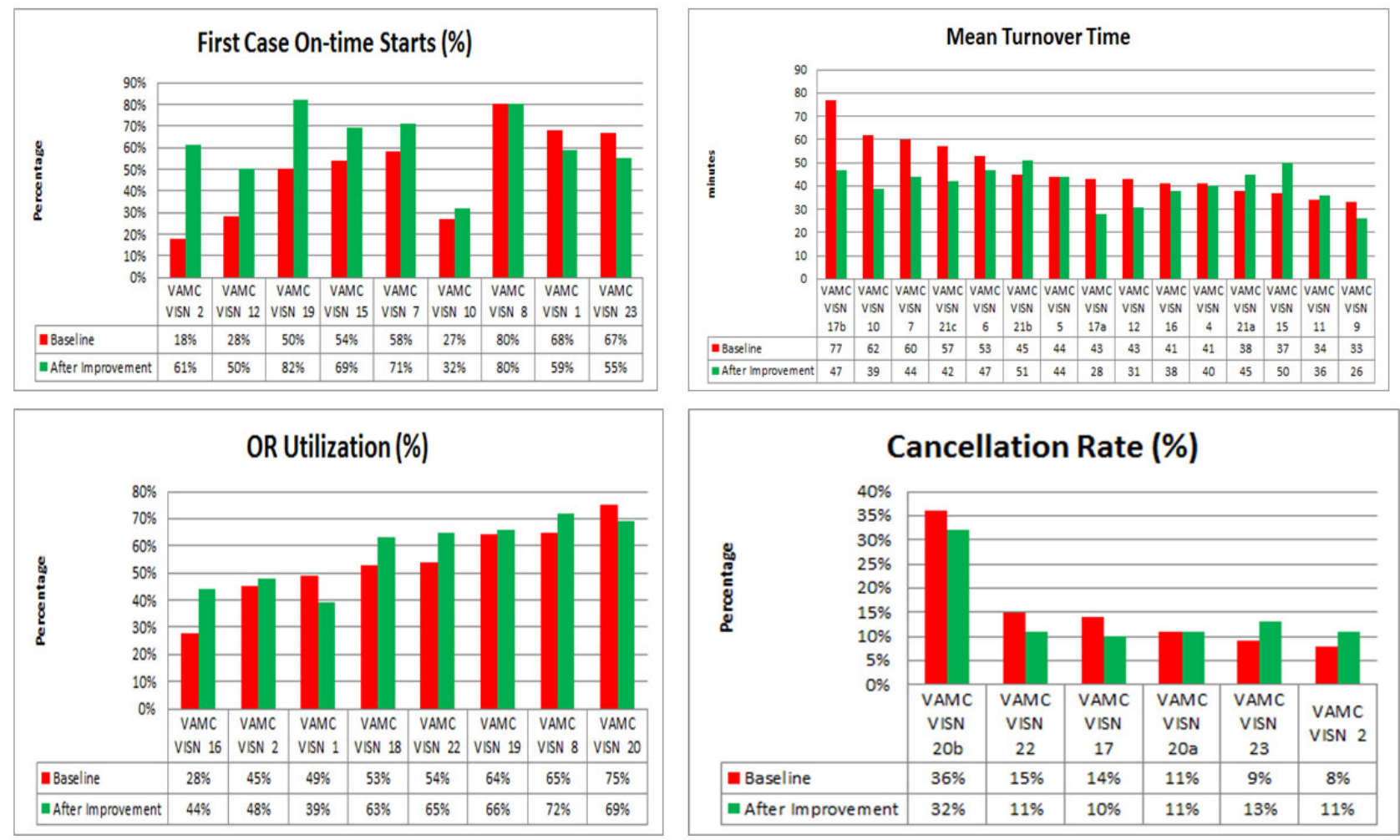

Figure 6. Summary of Metrics

\section{Discussion}

The modified collaborative model adopted for the SFII successfully enhanced the OR performance of participating teams and generated significant cost savings through better operating efficiency. This model resulted in improved first time starts, decreased turnover time, decreased cancellation rates and improved OR utilization. Although not specifically analyzed, the purpose for increasing OR utilization was intended to increase the number of surgical procedures to be scheduled and performed in the OR thereby decreasing patient wait time for surgery, decreasing patient referrals to another health care system, and improving overall patient and staff satisfaction.

Figure 6 supports the expectation that there will naturally be differing levels of improvement outcomes due to the inherent variance of different teams and facilities. ${ }^{[15,21-25]}$ We were 
able to identify similarities among successful teams such as active participation, following guidelines, and on-time task completion. Regarding those facilities who had a drop in performance on some of the measures following the intervention period, this can be explained by natural occurrences in a dynamic system such as purchase order delays, teams facing challenges as PDSAs were implemented, staff shortage (e.g., away for training or delays in hiring new staff), arrival of new residents, or staff turnover which could cause a change in prescribed treatment.

The Cost Savings tool was essential to aim selection and provided a standard process to determine which areas of improvement would potentially produce the most cost savings if the PI efforts were sustained. By projecting the financial benefits, the approach to Cost Savings calculation also helped to justify obligating staff time to the PDSA cycles and encouraged the teams to sustain and spread the achievements.

Feedback gathered from the teams indicated that they felt the staff were well trained and knowledgeable and were able to lead them down the right path for improvement. They suggested shortening the RPIWs to less than a week and possibly completing more of them. In addition, the teams indicated that they would appreciate even more pre-planning.

\section{Transferability and limitations}

This paper describes how the combined efforts of organizational structures in the VA designed to promote and support facility improvement capability (i.e., the VERC and the System Redesign and Improvement office), the NSO and local teams resulted in significant improvement in OR performance. Among some this may beg the question: is this approach transferable to community or academic hospitals who may not have the type of support for local teams that the VA sites did? We would submit that while the organizational infrastructure elements certainly provided the expertise and focus for large multi-center improvement, the tools and techniques used to foster process and performance improvement at the local level are certainly reproducible on a smaller scale. The principles of using PDSA approaches, flow-charting processes and assessing the value streams associated with them, constructing teams of stakeholders in the processes, performing “deep dives” or RPIWs, deciding on applicable measures and targets, and garnering leadership support are all local level functions that could be replicated at individual hospitals. The success of such a local effort would certainly be enhanced by the availability of a local improvement professional (e.g., Lean Black Belt or equivalent), but even in the absence of one, could be accomplished by a motivated group with review of freely available improvement literature, including some of the references included at the end of this paper.

Future research into the approaches used for OR performance improvement could focus on such smaller scale approaches and what the most fruitful modifications to our larger-scale effort might entail. Other areas of interest might include the sustainability of the improvements made in performance. Improvement methodology typically addresses sustainability and spread of improvements with techniques that include run-charts and commitment by teams to periodically review performance. These reviews are usually at predetermined intervals designed to allow for timely interventions in the event of performance deterioration. One of the biggest challenges in improvement science is the entropy that accompanies a process improvement over time.

\section{LESSONS LEARNED}

There was an assortment of factors associated with less successful teams, such as disorder amongst the numerous departments in the complex workflow of the OR, changes not affecting system performance as expected, and lack of previous experience with process improvement. The lack of leadership support resulted in a shortage of resources and failure to sustain achievements or teams not being able to improve their metrics in this project. These challenges hindered teams, making them less effective from achieving success during the Collaborative.

While the modified collaborative model was designed to address many of the challenges teams experienced in applying the IHI model to previous PI projects, we identified the following lessons learned to further develop and improve future improvement initiatives:

\section{(1) Pre-planning}

Teams that did not complete tasks during pre-planning struggled with the preparation of the improvement initiative. Therefore, time during the RPIW event week was spent defining problems and establishing performance baseline rather than completing implementation plans and testing change ideas. This resulted in reduced achievable improvement.

\section{(2) RPIWs}

Teams that failed to finish all the planned work of RPIWs faced problems later due to incomplete project charters, detailed implementation plans, and/or results of pilot tests of some of the change ideas. This adversely impacted the effectiveness of PDSA cycles because the project scope and implementation plans required continual modifications. 
(3) Implementation

If IEs did not establish strong and trusting relationships with the teams, the teams would not be open to communicate obstacles and tended not to submit deliverables on time to receive timely feedback and guidance. Moreover, teams with poor internal trust and communication had difficulty tracking progress and struggled to deliver improvement results.

(4) Leadership Involvement

The teams that lacked facility leadership support and pressure to progress did not always implement changes and did not always consider improvements as an integral part of their daily work. Alternatively, the teams whose facility leadership provided support and emphasized progression observed more successful outcomes than the teams whose leadership was less or minimally involved.

After the completion of the collaborative, an important final step was the success of sustainment and spread efforts. Those teams with more successful sustainment and spread experienced stronger facility leadership support, met regularly to identify barriers and analyze data, and utilized the tools given during the collaborative. Barriers to successful sustainment and spread were lack of leadership support, not monitoring data regularly or meeting regularly, and not following the provided sustainability plan.

The offices of SR, NSO, and VA-CASE took all of these lessons learned into consideration when planning and carrying out a subsequent SFII in Fiscal Year 2014-16 to sustain and spread efforts. ${ }^{[26]}$

\section{COnClusion}

Although there were challenges during the modified collaborative, teams were able to improve operations in surgical flow by enhancing first case on-time start, mean turnover time, cancellation rate, and OR utilization while observing a posi- tive Cost Savings and overcoming challenges experienced in a traditional IHI collaborative model. To lay foundation for success for future SFII, it is strongly recommended that the teams are monitored to follow guidelines and complete preplanning work, finish all planned RPIW work, and complete checklist tasks. It is also recommended to secure facility leadership support of the improvement initiative and establish an initial rapport between IEs and the facility improvement team focusing on trust and communication. Following these recommendations, future implementation of PI in surgical flow should observe fewer barriers to success and more outstanding improvements in surgical flow.

\section{ACKNOWLEDGements}

The authors would like to thank the Industrial Engineers, Shaiju Eapen, Pranav Radhakrishnan, and Shruthi Musunuri, and the VERC VA-CASE faculty, Jamie Workman-Germann, Carlos Garcia, Russell Cech, Sandra Serrano, George Ponte, Deanna Suskovich, Phillip Swearingen, and Brian Poyner, for their dedicated work on this project. Additionally, thank you to Nancy Fink for her work. Lastly, thank you to Amanda Kovach and Corrie Stewart for editing and proofreading the manuscript.

\section{FUNDERS}

The work described was funded and led by the Department of Veterans Affairs Office of Systems Redesign and Improvement, National Surgery Office and the Veterans Engineering Resource Center.

\section{CONFlicts of InTEREST Disclosure}

All authors are employed full time by the Department of Veterans Affairs. All authors have declared no potential conflicts of interests with respect to the authorship, research and commercial value of publishing this article. The views expressed within are solely those of the authors and do not necessarily represent the views of the Department of Veterans Affairs or the United States government.

\section{REFERENCES}

[1] Guerricro F, Guido R. Operational research in the management of the operating theatre: A survey. Health Care Management Science. 2011; 14(1): 89-114. PMid: 21103939. https://doi.org/10.1 007/s10729-010-9143-6

[2] Macario A, Vitez T, Dunn B, et al. Where are the costs in perioperative care? Analysis of hospital costs and charges for inpatient surgical care. Anesthesiology. 1996; 83(6): 1138-1144. https://doi.org/10.1097/00000542-199512000-00002

[3] Institute for Healthcare Improvement. The Breakthrough Series:
IHI's Collaborative Model for Achieving Breakthrough Improvement. 2003.

[4] Bidassie B, Davies ML, Stark R, et al. VA experience in implementing Patient-Centered Medical Home using a breakthrough series collaborative. Journal of General Internal Medicine. 2014; 29(Suppl 2): S563-S571.PMid: 24715402. https://doi.org/10.1007/s1 1606-014-2773-5

[5] Butler A, Canamucio A, Macpherson D, et al. Primary care staff perspectives on a virtual learning collaborative to support medical home implementation. Journal of General Internal Medicine. 2014; 
29(Suppl 2): 579-588. PMid: 24715388. https ://doi.org/10.1 007/s11606-013-2668-x

[6] Jackson GL, Powell AA, Ordin DL, et al. Developing and sustaining quality improvement partnerships in the VA: The colorectal cancer care collaborative. Journal of General Internal Medicine. 2010; 25(Suppl 1): 38-43. PMid: 20077150. https ://doi .org/10.100 7/s11606-009-1155-x

[7] Mills PD, Waldron J, Quigley PA, et al. Reducing falls and fall related injuries in the VA system. Quality and Safety in Health Care. 2003; 1: 25-33.

[8] Weeks WB, Mills PD, Dittus RS, et al. Using an improvement model to reduce adverse drug events in VA facilities. The Joint Commission Journal on Quality Improvement. 2001; 27(5): 243-254 https ://doi.org/10.1016/S1070-3241(01) 27021-7

[9] Langley GL, Moen R, Nolan KM, et al. The improvement guide: A practical approach to enhancing organizational performance. 2 nd ed. San Francisco: Jossey-Bass Publishers; 2009.

[10] Anderson JC, Rungtusanatham M, Schoeder RG. A theory of quality management underlying the Deming management method. Academic Management Review. 1994; 19(3): 472-509.

[11] Nembrand IM. Quality and patient safety: Learning and improving in quality improvement collaboratives: Which collaborative features do participants value most? Health Research and Education Trust. 2009; 42(2): 359-378.

[12] Ovretveit J, Bate P, Cleary P, et al. Quality collaboratives: Lessons from research. Quality and Safety in Health Care. 2002; 11(4): 343351. https://doi.org/10.1136/qhc.11.4.345

[13] Mills PD, Weeks WB. Characteristics of successful quality improvement teams: lessons from five collaborative projects in the VHA. The Joint Commission Journal on Quality and Safety. 2004; 30(3): 152162. https : //doi .org/10.1016/S1549-3741 (04) 30017-1

[14] Sales A, Moscoviece I, Lurie N. Implementing CQI projects in hospitals. The Joint Commission Journal on Quality Improvement. 2001; 26(8): 321-331.

[15] Shortell SM, O'Brien JL, Carman JM, et al. Assessing the impact of continuous quality improvement/total quality management: Con- cept versus implementation. Health Service Research. 1995; 30(2): 377-401. PMid: 7782222

[16] Parker VA, Wubbenhorst WH, Young GJ, et al. Implementing quality improvement in hospitals: The role of leadership and culture. American Journal of Medical Quality. 1999; 14(1): 64-69. PMid: 10446665. https://doi.org/10.1177/106286069901400109

[17] Liker J, Meier D. The Toyota Way Fieldbook New York: McGrawHill; 2006.

[18] Bidassie B, Williams LS, Woodward-Hagg H, et al. Key components of external facilitation in an acute stroke quality improvement collaborative in the Veterans Health Administration. Implementation Science. 2015; 10(69). https : //doi.org/10.1186/s13012 -015-0252-y

[19] Nelson EC, Splaine ME, Batalden PB, et al. Building measurement and data collection into medical practice. Annals of Internal Medicine. 1998; 128(6): 460-466. PMid: 9499330. https : //doi.org/10.7326/0003-4819-128-6-199803150-00007

[20] VHA SFII Handbook. VHA Surgical Flow Improvement Initiative handbook. 2012.

[21] Bero LA, Grilli R, Grimshaw JM, et al. Closing the gap between research and practice: An overview of systematic reviews of interventions to promote the implementation of research finds. British Medical Journal. 1998; 317(7156): 465-468. PMid: 9703533. https://doi .org/10.1136/bmj.317.7156.465

[22] Fried B, Toppings S, Rundall T. Groups and teams in health service organizations. In Shortell S, Kalunzny A, editors. Health Care Management: Organization Design and Behavior. Albany: Delmar; 2000. 154-190 p.

[23] NHS Centre for Reviews and Dissemination. Getting evidence into practice. 1999.

[24] Ovretveit J. Integrated Quality Development for Public Healthcare Oslo: Norwegian Medical Association; 1999. PMid: 10847886.

[25] Plsek P. Spreading good ideas for better healthcare: a practical toolkit. 2002.

[26] Bidassie B, Gunnar W, Starr L, et al. Data driven process to improve VA surgical flow. International Journal of Health Care Quality Assurance. 2017; 30(8) 